Supplemental Material for

\title{
Fine particles from Independence Day fireworks events: chemical characterization and source apportionment
}

Jie Zhang ${ }^{1,}$ Sara Lance ${ }^{1}$, Jeffrey M. Freedman ${ }^{1}$, Yele Sun $^{2}$, Brian A. Crandall ${ }^{1}$, Xiuli Wei ${ }^{1,3}$, James J. Schwab ${ }^{1}$

${ }^{1}$ Atmospheric Sciences Research Center, University at Albany, State University of New York;

${ }^{2}$ State Key Laboratory of Atmospheric Boundary Layer Physics and Atmospheric Chemistry, Institute of Atmospheric Physics, Chinese Academy of Sciences, Beijing, China

${ }^{3}$ Anhui Institute of Optics and Fine Mechanics, Chinese Academy of Sciences, Hefei, China

Correspondence to:James J. Schwab (jschwab@albany.edu) 


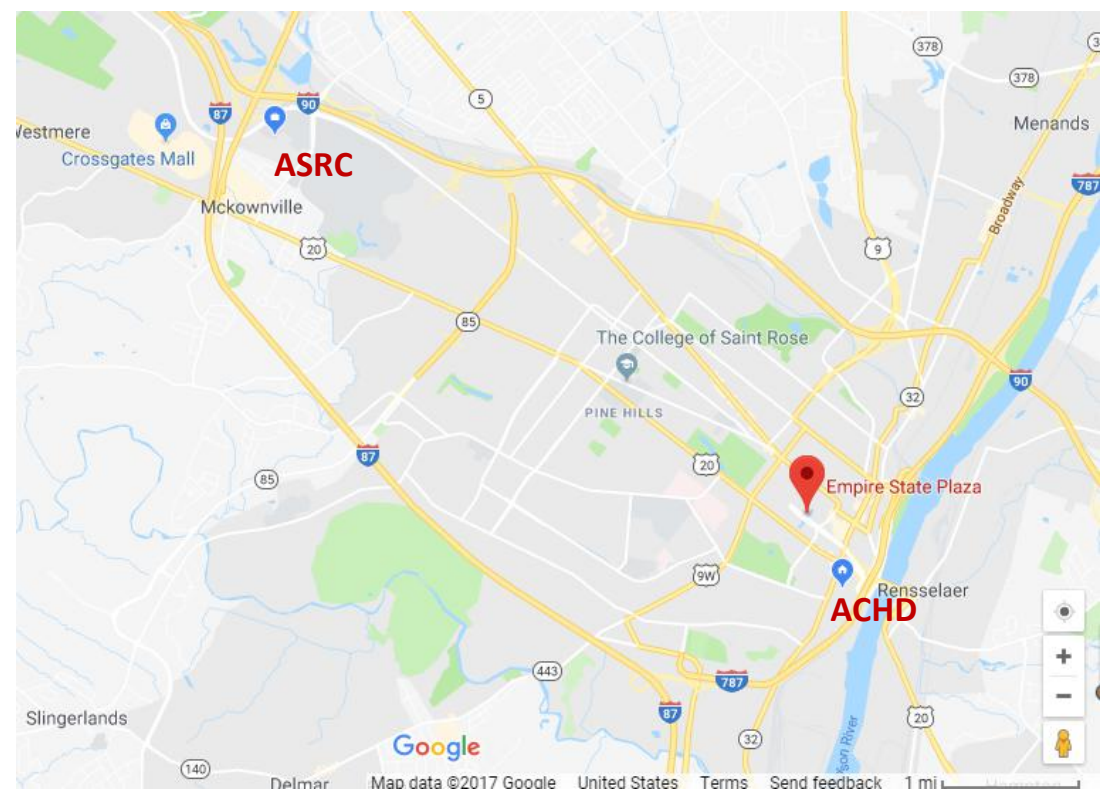

Figure S1. Locations of measurement sites (from Google maps)

ASRC: Atmospheric Sciences Research Center, University at Albany - the uptown site; ACHD: Albany County Health Department - downtown measurement site; Empire State Plaza: the fireworks burning location.

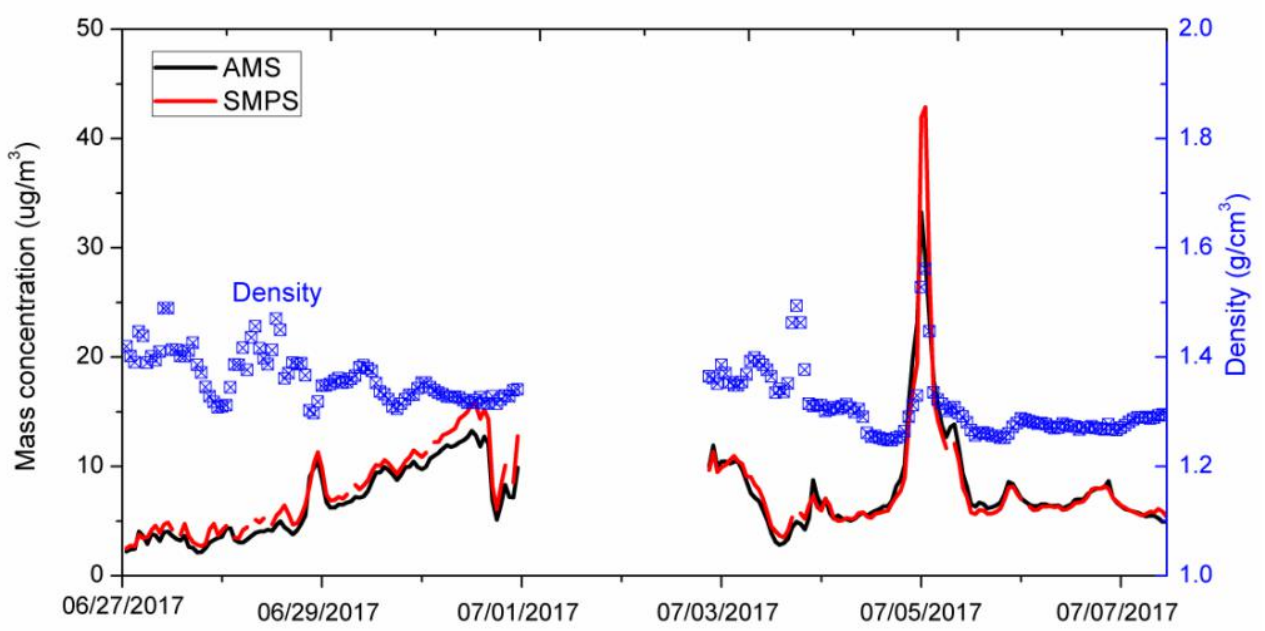

Figure S2. Time series of aerosol density and mass concentration determined by the AMS and the SMPS

The collection efficiencies (CE) of 0.7 was chosen for organic compounds to best match the aerosol mass concentration measured by AMS and SMPS. For SMPS data, the density of ambient aerosol was calculated based on the mass concentration of different inorganic salt and the organic compounds determined by the AMS (Zhang et al., 2005). It assumes that the organic composition (containing organopotassium) had an average density of $1.20 \mathrm{~g} \mathrm{~cm}^{-3}$, and uses densities of $\left(\mathrm{NH}_{4}\right)_{2} \mathrm{SO}_{4}$ as $1.79 \mathrm{~g} \mathrm{~cm}^{-3}, \mathrm{NH}_{4} \mathrm{NO}_{3}$ as $1.72 \mathrm{~g} \mathrm{~m}^{-3}, \mathrm{~K}_{2} \mathrm{SO}_{4}$ 
as $2.66 \mathrm{~g} \mathrm{~m}^{-3}, \mathrm{KNO}_{3}$ as $2.11 \mathrm{~g} \mathrm{~m}^{-3}$ and $\mathrm{KCl}$ as $1.99 \mathrm{~g} \mathrm{~m}^{-3}$ respectively. The averaged ambient density was then calculated following (Lee et al., 2015):

$$
\rho_{\text {ambient }}=\frac{m_{\text {Total }}}{\frac{m_{\text {organic }}}{\rho_{\text {organic }}}+\frac{m_{\left(\mathrm{NH}_{4}\right)_{2} \mathrm{SO}_{4}}}{\rho_{\left(\mathrm{NH}_{4}\right)_{2} \mathrm{SO}_{4}}}+\frac{m_{\mathrm{NH}_{4} \mathrm{NO}_{3}}}{\rho_{\mathrm{NH}_{4} \mathrm{NO}_{3}}}+\frac{m_{\mathrm{K}_{2} \mathrm{SO}_{4}}}{\rho_{\mathrm{K}_{2} \mathrm{SO}_{4}}}+\frac{m_{\mathrm{KNO}_{3}}}{\rho_{\mathrm{KNO}}}+\frac{m_{\mathrm{KCl}}}{\rho_{\mathrm{KCl}}}}
$$

Where $\boldsymbol{\rho}$ is density, and $\boldsymbol{m}$ is the mass concentration.

For much of the measurement period, the density of the ambient aerosol was estimated to be in the range of 1.2-1.4 $\mathrm{g} \mathrm{cm}^{-3}$. However it was as high as $1.56 \mathrm{~g} \mathrm{~cm}^{-3}$ during Independence FW event period, which was caused by the huge emissions of inorganic salts. The density estimated in this study was smaller than the value of Zhang et al. (2010). The main reason is that at Albany, even during Independence FW event period, organics still remained the dominant component, while at Beijing (Zhang et al., 2010), inorganics made larger contributions, leading to a higher average density. Another point to consider is that here we assumed the K-rich organics' density to be $1.2 \mathrm{~g} \mathrm{~cm}^{-3}$, and this may cause an underestimate in the average density. 

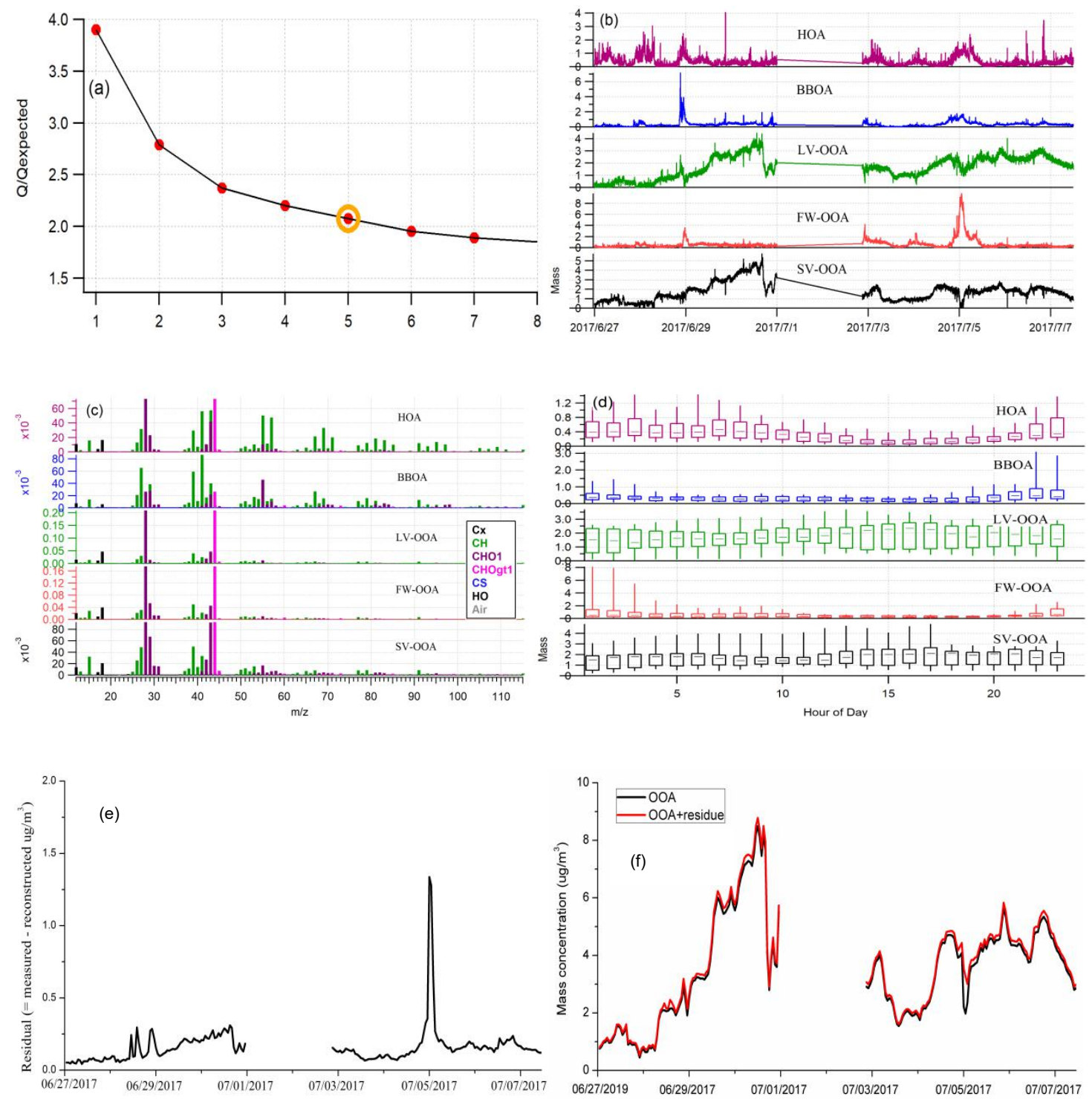

Figure S3. a): The PMF quality of fit parameter $\left(Q / Q_{\text {expected }}\right)$ as a function of the number of factors; b): the time series of mass concentration of each organic aerosol factor; c): Mass spectra of five identified OA component factors; $d$ ): mass concentration diurnal variation of each organic aerosol factor; e): the variation of residual (measured - reconstructed ) of PMF result; $f$ ): the mass concentration time series of OOA (LV-OOA+SV-OOA) and OOA+residual.

The PMF reconstruction shown in Fig.S3f indicates that OOA (the sum of SV-OOA and LV-OOA) dropped dramatically during Independence Day FW event period. This is inconsistent with the assumption that these two were predominately local background aerosol and should not have dramatic variation with time. Much of this dramatic drop could be the result of over-assignment of FW-OOA or others, but even more likely is that the residual (Fig.S3e) would account for a substantial portion of the deficit. Figure S3e considers SV-OOA and LV-OOA together as OOA, and its time series and another obtained by adding OOA and the residuals. Noticeable structure still remains in the time series of the sum during the FW event, but the difference between two points during Independence Day FW event is smaller than $1 \mu \mathrm{g} \mathrm{m}^{-3}$, and is in an acceptable range. 

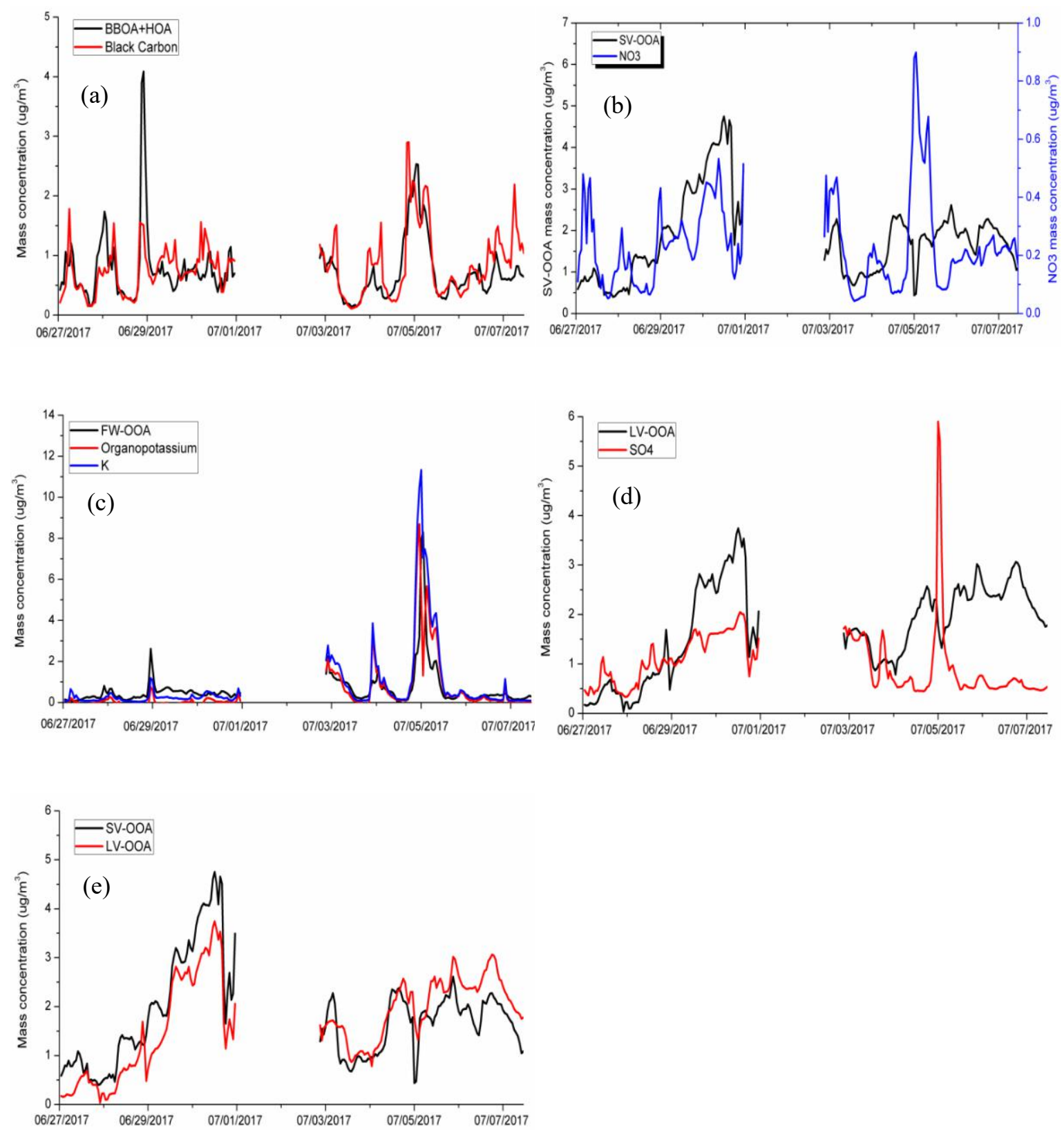

Figure S4. The time series of mass concentration of a): BBOA+HOA vs Black carbon (measured at ACHD); b): SV-OOA vs NO 3 ; c: FW-OOA vs Organopotassium and K; d): $\mathrm{LV}-\mathrm{OOA}$ vs $\mathrm{SO}_{4}$; e): LV-OOA vs SV-OOA 


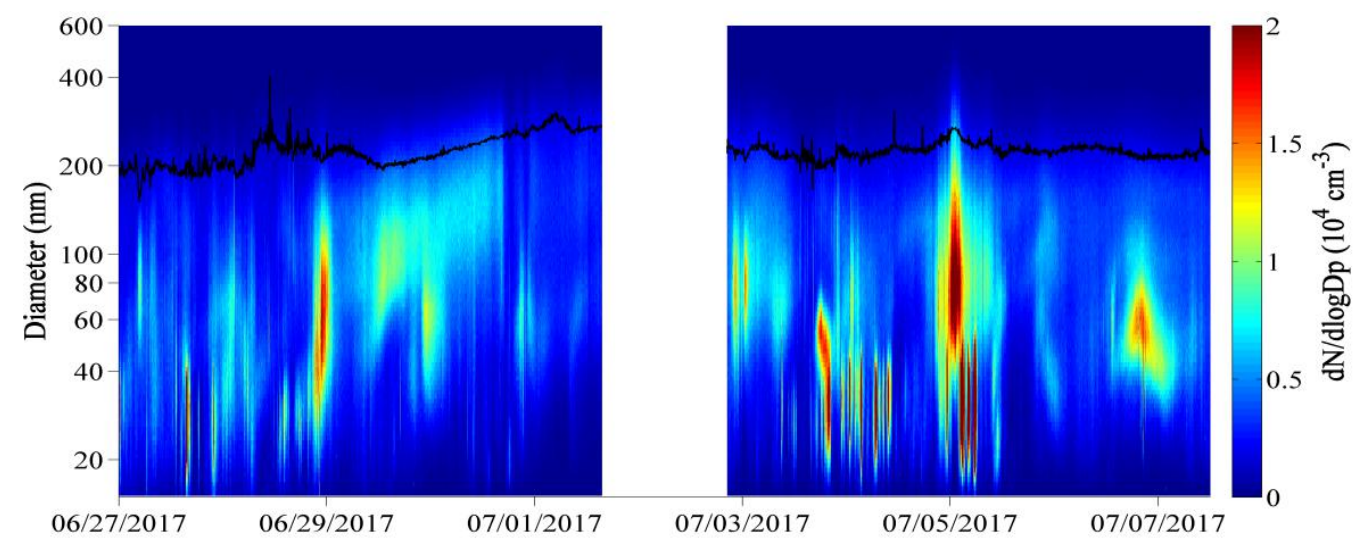

Figure S5. The number size distribution measured by SMPS (the black line indicates median aerosol volume diameter)

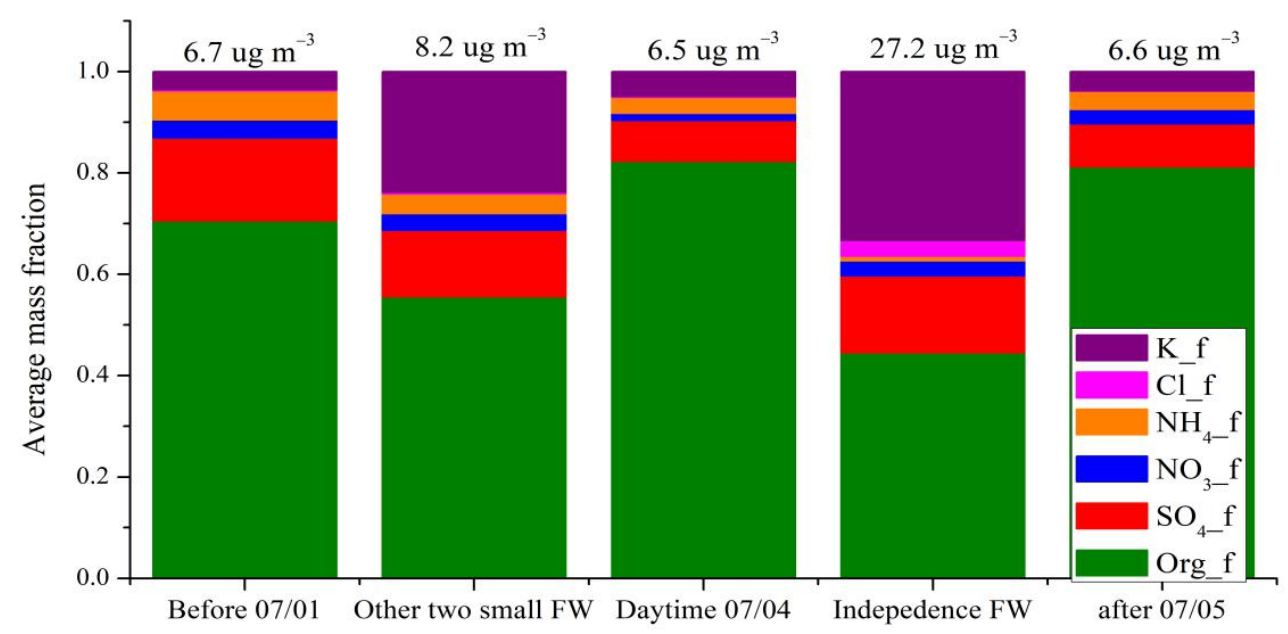

Figure S6. The averaged aerosol components mass fractions for different time intervals 


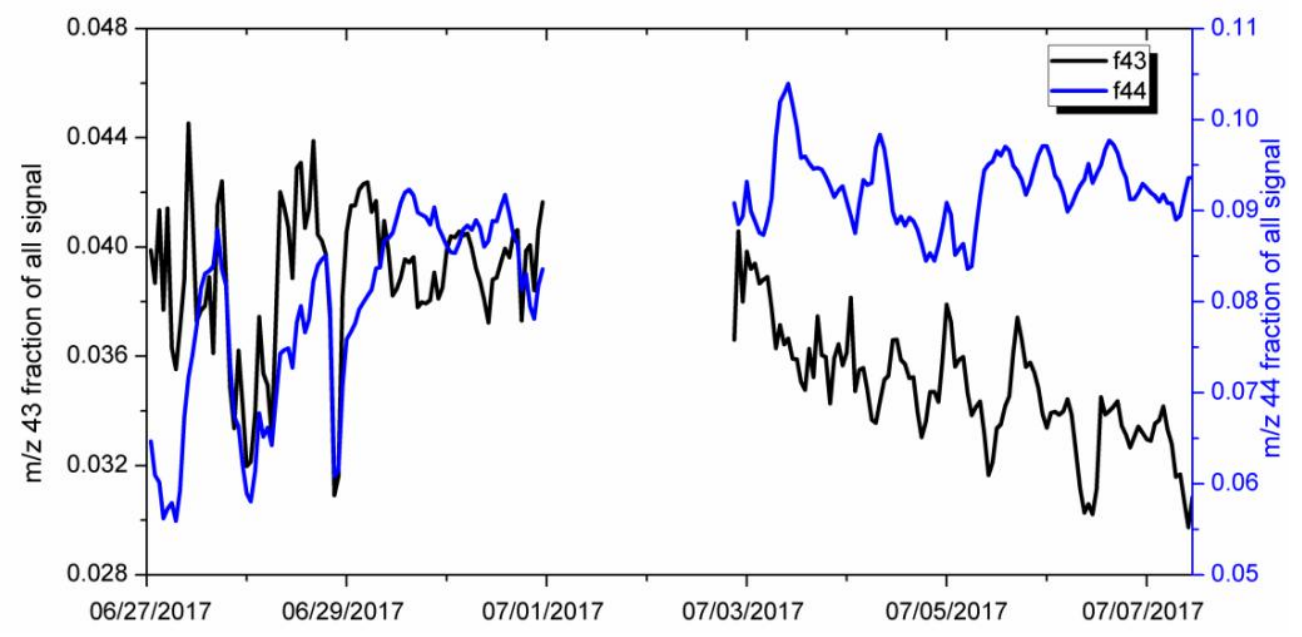

Figure S7. The time series of the contributions due to the $\mathrm{m} / \mathrm{z} 43$ and $\mathrm{m} / \mathrm{z} 44$ signals.

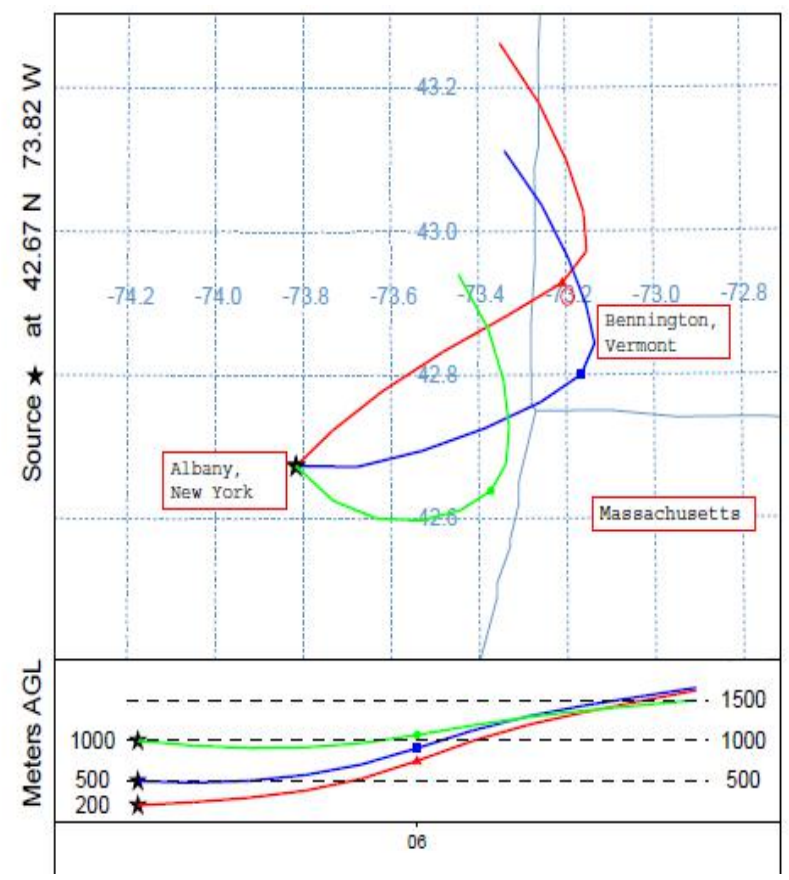

Figure S8. NOAA HYSPLIT 10-hour back trajectories for ambient air parcels over the ASRC sample site at Jul 5 07:00 EDT 


\section{References:}

Lee, B. P., Li, Y. J., Flagan, R. C., Lo, C., and Chan, C. K.: Sizing characterization of the fast-mobility particle sizer (FMPS) against SMPS and HR-ToF-AMS, Aerosol science and technology, 47, 1030-1037, doi:10.1080/02786826.2013.810809, 2013.

Zhang, M., Wang, X., Chen, J., Cheng, T., Wang, T., Yang, X., Gong, Y., Geng, F., and Chen C.: Physical characterization of aerosol particles during the Chinese New Year's firework events, Atmospheric Environment, 44, 5191-5198, doi:10.1016/j.atmosenv.2010.08.048, 2010.

Zhang, Q., Canagaratna, M. R., Jayne, J. T., Worsnop, D. R., and Jimenez, J. L.: Time-and size-resolved chemical composition of submicron particles in Pittsburgh: Implications for aerosol sources and processes, Journal of Geophysical Research: Atmospheres, 2005, 110,D07S09, 1-19, doi:10.1029/2004JD004649, 2005. 